\title{
Risk Analysis and Research on Early-Warning System of Sport under High Temperature and High Humidity Environment
}

\author{
Dongqing Gao \\ Shanghai University of Engineering Science, Shanghai, 201620 \\ gdq1976@sohu.com
}

\begin{abstract}
High temperature and high humidity is an unavoidable environmental condition of sports training and exercise. Recognizing the risk under high temperature and high humidity environment will help avoid the risk of sports injury accident under such environment. This paper through the literature analysis, qualitative analysis and system analysis, to make out of identification, assessment and early warning on risk of sport under high temperature and high humidity environment. And, ultimately, to build an early warning system for movement risk under the conditions of high temperature and high humidity environment. Through this system, we may minimize or avoid the sports risk under conditions of high temperature and high humidity environment.
\end{abstract}

Keywords- high temperature and humidity; sports risk; early warning system; build

\section{INTRODUCTION}

According to the relationship between the environmental temperature and the heat balance of human body, usually when it is more than $35^{\circ} \mathrm{Cabove}$ the living environment and more than $32^{\circ} \mathrm{Cabove}$ of the production environment as high temperature, relative humidity above $60 \%$ in the environment is called high humidity environment. The body will occur exercise heat stress when training or exercise in a hot and humid environment, the effect will be comprehensive reflection of exercise stress superimposed on the thermal stress. But the body in high temperature and high humidity environment, exercise stress and heat stress are mutually reinforcing, it will seriously affect the athletes' athletic ability and physical health. Therefore, from the point of view of the protection of the health of Human Movement, this research exploring and constructing the early warning system for sports risk under high humidity and high temperature conditions, in order to guide the competitive sport and fitness exercise under high humidity and high temperature conditions.

\section{SYSTEM DESIGN IDEAS AND RESEARCH METHODS}

\section{A. System design ideas}

The early warning system for sports risk under high temperature and high humidity environment is to monitor and predict the changing of sports risk status under high temperature and high humidity environment through the choice of three sensitive norms of sports environment, sports load and physical function, based on the logical analysis and mathematical model. Specific design ideas: first, identify sports risk under the high temperature and high humidity environment, establish risk index system of sports under high temperature and high humidity; then, screening and assessing on these risk factors, using the principle of the "signal" to divide risk factors into red, yellow and green warning signals; finally, according to these risk warning signals to monitor and safety-guide for human body motion under high temperature and high humidity environment.

\section{B. Research methods}

1) Literature analysis: In accordance with the collected information of high temperature and high humidity, movement and the risks, analysis, and summarizes the existing problems.

2) Qualitative analysis: using qualitative methods, analysis the unexpected risk factors may occur in organism when sport under high temperature and high humidity environment, analysis the characteristics, types and sources of these risk factors.

3) System analysis: by means of system methods, we study on elements of early warning system of risks under high temperature and high humidity and their relationships, study the processes of the sports risk early warning system, and study the specific organizational issues of the entire system through the construction of organizational structure.

\section{ANALYSIS ON THE RISKS OF SPORTS UNDER HIGH TEMPERATURE AND HIGH HUMIDITY ENVIRONMENT}

A .Identification of the risks of sports under high temperature and high humidity environment

Risk identification include the identification of risk factors, risk conditions; to describe its risk characteristics and the possible consequences; to identify the risk classification. Risk identification is the basic works of risk management. Does the risk factor identification methods correct or not will do greatly affect result of the following risk assessment and risk management. Any incorrect definition to risk will lead to further risk. Risk identification makes risk estimation and evaluation of more effective and 
efficient by providing the necessary information.

Based on state analysis to movement under the high temperature and high moisture, this study makes identification of sports risk under high temperature and high humidity environment from two aspects of the induced movement risk including internal factors (individual situations and potential cardiovascular and cerebrovascular disease) and external factors (Sport and exercise environment ), built sports risk index system under the high temperature and high humidity conditions ( Table 1)

TABLE1 SPORTS RISK INDEX SYSTEM UNDER THE HIGH TEMPERATURE AND HIGH HUMIDITY CONDITIONS

\begin{tabular}{ccc}
\hline First level index & Second level index & Third level index \\
\hline internal factors $\mathrm{X}_{1}$ & Individual situations $\mathrm{X}_{11}$ & Sex $\mathrm{X}_{111}$ \\
& & Age $\mathrm{X}_{112}$ \\
& Health condition $\mathrm{X}_{12}$ & ${\text { Underlying diseases } \mathrm{X}_{121}}$ \\
external factors $\mathrm{Y}_{1}$ & Sports features $\mathrm{Y}_{11}$ & Sports events $\mathrm{Y}_{111}$ \\
& & Sports property $\mathrm{Y}_{112}$ \\
& & Exercise intensity $\mathrm{Y}_{113}$ \\
& & Sports duration $\mathrm{Y}_{114}$ \\
& Sports environment $\mathrm{Y}_{12}$ & Ambient temperature $\mathrm{Y}_{121}$ \\
& & Ambient humidity $\mathrm{Y}_{122}$ \\
& & Ventilation status $\mathrm{Y}_{123}$ \\
\hline
\end{tabular}

\section{B. Assessment of sports risk under the high temperature and high humidity conditions}

Risk assessment of sport under high temperature and high humidity environment conditions is based on risk identification, by combining quantitative and qualitative analysis methods, estimating and predicting risk amount when risk occur. Assessment sports risk under high temperature and high humidity environment conditions by use of the list ranking method, risk calculation formula is:
$\mathrm{Rv}=\mathrm{P} * \mathrm{~S} * \mathrm{C}$, wherein $\mathrm{Rv}$ represents risk amount, $\mathrm{P}, \mathrm{S}, \mathrm{C}$ denote respectively the athletic sudden death possibility, seriousness and controllability. This study uses 5 levels of evaluation, each level corresponding value respectively 5,4 , 3,2 and 1 points, which calculates risk value is greater, the greater the risk were, finally obtains the risk assessment results of sport under high temperature and high humidity conditions ( Table 2).

TABle 2 AsSESSMENT RESUlts OF SPORT RiSK UNDER THE High TEMPERATURE AND High HuMIDITY CONDITIONS

\begin{tabular}{ccc}
\hline Risk factor & Risk amount (score) & Sort sequence \\
\hline Sex $\mathrm{X}_{111}$ & $29.3 \pm 9.3$ & 10 \\
Age $\mathrm{X}_{112}$ & $43.2 \pm 8.1$ & 8 \\
${\text { Underlying diseases } \mathrm{X}_{121}}^{\text {Sports events } \mathrm{Y}_{111}}$ & $131.3 \pm 16.9$ & 1 \\
${\text { Sports property } \mathrm{Y}_{112}}^{\text {Exercise intensity } \mathrm{Y}_{113}}$ & $32.1 \pm 6.3$ & 6 \\
Sports duration $\mathrm{Y}_{114}$ & $57.4 \pm 15.1$ & 2 \\
Ambient temperature $\mathrm{Y}_{121}$ & $90.5 \pm 11.2$ & 7 \\
Ambient humidity $\mathrm{Y}_{122}$ & $51.2 \pm 10.1$ & 3 \\
Ventilation status $\mathrm{Y}_{123}$ & $87.3 \pm 12.3$ & 5 \\
\hline
\end{tabular}

\section{Risk early-warning of sport under the high temperature and high humidity conditions}

By risk assessment of sport under high temperature and high humidity environment conditions, we got risk factors sorting of sport under high temperature and high humidity environment. According to study on the relationship between risk measurement and risk level by Zhou Zhipeng et al, when $\mathrm{Rv} \geq 90$ as high level risk, when $40 \leq \mathrm{Rv}<90$ for moderate risk, when $\mathrm{Rv}<40$ for low level risk. Therefore, the risk factors under high temperature and high humidity environment conditions, underlying disease, and exercise intensity are high risk factors, gender, sport as low risk factors, the rest are moderate risk factors. At the same time, according to the level of risk, output of risk warning signals by using a "light", bright "red" when the body is in the high risk level, bright "yellow light" in the medium risk level, light "green light" when in low risk level ( Table 3).

TABLE3 Risk LEVEL AND WARNING SignAl of SPORTS UNDER High TEMPERATURE AND High HuMidity ENVIRONMENT

\begin{tabular}{|c|c|c|c|l|}
\hline Risk Amount & Risk Level & Risk Factors & Warning Signal & \multicolumn{1}{|c|}{ Risk response } \\
\hline $\mathrm{Rv} \geq 90$ & High & $\mathrm{X}_{121}, \mathrm{Y}_{113}$ & Red light & $\begin{array}{l}\text { Prohibit high intensity sport, Key } \\
\text { supervision }\end{array}$ \\
\hline $40 \leq \mathrm{Rv}<90$ & middle & $\begin{array}{c}\mathrm{X}_{112}, \mathrm{Y}_{113}, \mathrm{Y}_{114}, \mathrm{Y}_{121}, \\
\mathrm{Y}_{122}, \mathrm{Y}_{123}\end{array}$ & Yellow light & Risk control, sport load test \\
\hline $\mathrm{Rv}<40$ & low & $\mathrm{X}_{111}, \mathrm{Y}_{111}$ & Green light & $\begin{array}{l}\text { Normal movement, } \\
\text { avoidance }\end{array}$ \\
\hline
\end{tabular}




\section{ESTABLISHMENT OF RISK WARNING SYSTEM OF SPORTS UNDER HIGH TEMPERATURE AND HIGH HUMIDITY ENVIRONMENT}

\section{A. Main process of the system}

According to the risk analysis of sport under high temperature and high humidity environment, process of establishing risk early warning system mainly includes the following four parts: a clear warning, finding warning sources, analysis of warning sign and forecasting warning degrees; Warning determining is the precondition, is research foundation of monitoring and early warning, and finding warning sources analysis warning sign, belonging to the qualitative and quantitative analysis to influence factors. forecasting warning degrees is judgments to alarm severity.

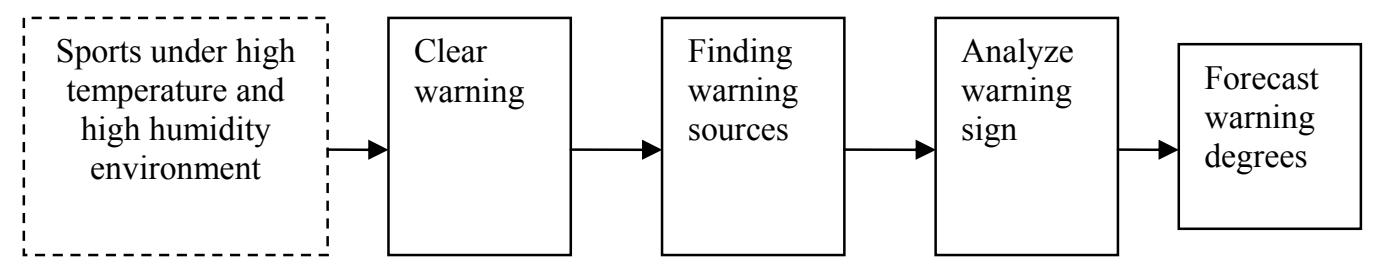

FIGURE 1: MAIN PROCESS OF THE EARLY WARNING SYSTEM

\section{$B$. The main structure of the system}

Based on the demand analysis of risk early-warning system of sport under high temperature and high humidity conditions, it is divided into 4 modules according to its function: personal health information module, check module, sports risk assessment module and early-warning module. System function structure as shown in figure 2 .

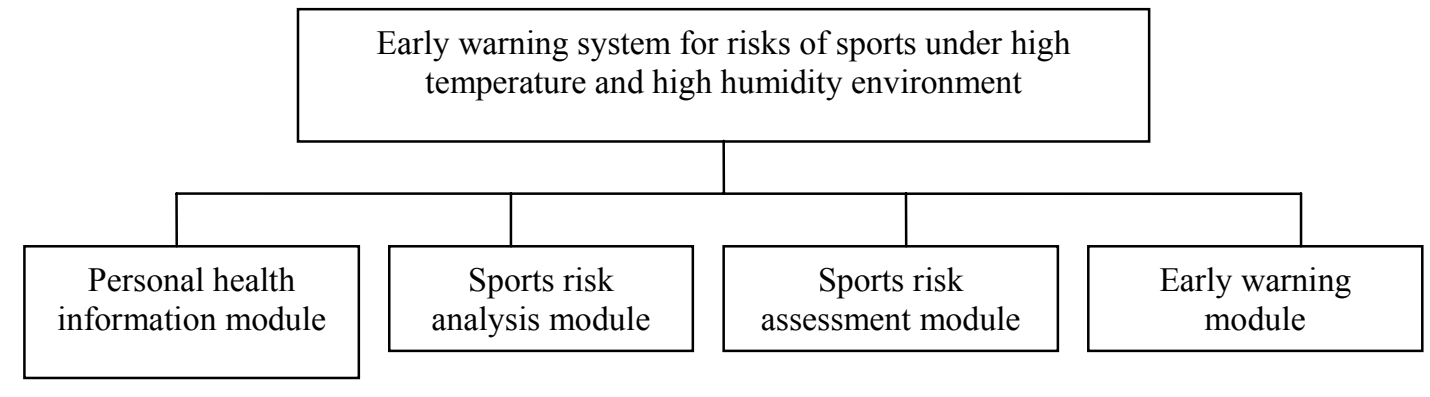

Figure 2: The MAIN STRUCTURE OF THE System

\section{The main function of the system}

The system is mainly used for early warning to sports risk in high temperature and high humidity conditions, through relevant means and methods to guide and help people to understand the sports risks under conditions of high temperature and high humidity environment, so as to achieve the purpose of avoiding risks. Its main functions include:

1) Personal health information module. Including name, gender, age, past medical history, family history, basic health information, and general health examination, lifestyle, health status and medication, etc.

2) Sports risk analysis module. High temperature and high humidity conditions risk is mainly divided into two categories: one is the body's own health status, the two is the outside environment and load. The health of human body is the main factors to induce risks, which include the presence of potential disease, health and sports ability; outside environment and load including temperature, humidity, exercise intensity, exercise duration and exercise load etc.

3) Sports risk assessment module. In view of sport risk exists in high temperature and high moisture conditions. The cardiopulmonary exercise testing is an effective method in risk assessment. We can use simple, convenient bench test. Bench test method: men and women using stepped high of $40 \mathrm{~cm}$ and $35 \mathrm{~cm}$. Measure peaceful pulse first, then make a metronome $30 / \mathrm{m}$ frequency stepped up and down the steps for 3 minutes, immediately test 3 recovery period pulse after the test finished at 1 to 1 half minutes, 2 to 2 half minutes, 3 to 3 half minutes; evaluate cardiovascular function through the test to the relevant data for the test object. Evaluation index $=$ (duration of pedal up and down movement (s) *100) / $(2 * 3$ times of pulse 
amount); Evaluation criteria: as for male, step test evaluation index of more than 67 for strong, 53-66 for relatively strong, 46-52 for general, below 45 for poor. As for female, step test evaluation index of more than 60 for strong, 49-59 for relatively strong, 42-48 for general, below 41 for poor.

4) Sports risk early-warning module. In the subsystem of sports risk early-warning, we should undertake reasonable division of risk early-warning interval, judge the risk amount is in a normal state, a state of alert or dangerous state. One is to delineate the warning interval: includes dividing the warning district and determining the warning limit, risk early-warning can be divided into five warning zone, namely I (low risk area), II (relative low risk area), III (moderate risk area), IV (relative high risk area), V (high risk area). Generally, we use 5 points for judging risk evaluation level, namely: "very good", "good", "general", "bad", "poor", mark a score of 5, 4, 3, 2, 1. So get the evaluation vector $\mathrm{C}=[5,4,3,2,1] \mathrm{T}$. Therefore, if $4<\mathrm{C} \leq 5$, the project risk in low risk area; if $3<\mathrm{C} \leq 4$, then at a relative low risk area; if $2<\mathrm{C} \leq 3$, were in the moderate risk area, need to pay attention to; if $1<\mathrm{C} \leq 2$, then in the high risk area, needs to be monitored; if $0<\mathrm{C} \leq 1$, were in high danger, need to take relevant measures. Two is a design of signal light display system, early warning system can take a similar traffic signal light signal display method, because the system has five warning interval, we can design "five lights" display system, namely the "blue light", "green light", "yellow light", "orange light", "red light" for identifying individual warning.

\section{CONCLUSIONS}

Through the identification, assessment and early-warning analysis on the risk of sports under high temperature and high humidity environment, and the application of risk management science and computer technology, we construct risk warning system of sports under high temperature and high humidity environment. The main function of the system is to collecting personal health information, analysis sport risk, and make risk assessment according to the risk status, then getting risk early-warning through the "signal lights" way. Through the system, we can effectively avoid the sports risk under high temperature and high humidity environment conditions, maximize prevent sport injury accidents under high temperature and high humidity conditions.

\section{REFERENCES}

[1] Hong Changqing, Yan Yi, Xie Minhao. Heat stress and sports. Journal of Beijing Sport University, 2004, 27(4):496-498.

[2] Qiu Renzhi, Zhu Shoucheng, Ye Zhuoming. Comparison of water and electrolyte metabolism when supply freshwater, saltwater under thermal environment.J. Industrial Health and Occupational Diseases, 1994, 20(3):142-146.

[3] Zhou Qing, Xu Ruxiang, Zhang Shizhong etc. Human biochemical changes before and after physical exercise under high temperature and high humidity environment. Chinese Journal of clinical rehabilitation, 2004, 8(30):6718-6719.

[4] R.W. Kenefick, C.M. Maresh, L. E. Armstrong, et al. Rehydration with fluid of varying tonicities: effects on fluid regulatory hormones and exercise performance in the heat. J Appl Physiol, 2007, 102(5):1899-1905.

[5] Wilk B, Timmons BW. Voluntary fluid intake, hydration status, and aerobic performance of adolescent athletes in the heat. Applied Physiology Nutrition And Metabolism-Physiologie Appliquee Nutrition Et Metabolisme,2010,35(6):834-841.

[6] Xing Cheng. Metabolism and supplementation of water salt when work in thermal environment. Journal of Military Hygiene, 1983, 9(2):66-71.

[7] Zhao Jiexiu, Feng Lianshi. High-temperature and high-humidity environment and sport fatigue. Chinese Journal of Sports Medicine, 2008, 27(2):238-242.

[8] Suzuki M, Shimizu T, Kawabe N, et al. Effects of carbohydrate and electrolyte solution replacement on metabolic and hormonal responses after a moderate endurance run in hot outdoor conditions. Japanese Journal of Physical Fitness and Sports Medicine, 1998, 47(4):427-441.

[9] Dabinett J, Reid K, James N. Educational strategies used in increasing fluid intake and enhancing hydration status in field hockey players preparing for competition in a hot and humid environment: A case study. International Journal of Sport Nutrition and Exercise Metabolism, 2001, 11(3): 334-348.

[10] Maughan RJ, Shirreffs SM, Ozgunen. Living, training and playing in the heat: challenges to the football player and strategies for coping with environmental extremes. Scandinavian Journal of Medicine \& Science in Sports, 2010, 20(3): 117-124.

[11] Futterman LG, Myerburg R. Sudden death in athletes: an update [J].Sports Med, 1998, 26(5):335-350.

[12] Robert E,Stephanie L,Charles L, et al. Sudden death in young adults: A 25-year review of autopsies in military recruits[J].Ann Intern Med,2004,141(11):829-835. 